\title{
Transient Stability Analysis of Photovoltaic System with Experimental Shading Effects
}

\author{
Abdelaziz Salah Saidi \\ King Khalid University, College of \\ Engineering, \\ Abha, Saudi Arabia \\ and Electric Systems Laboratory, \\ National Engineering School of Tunis, \\ Tunisia
}

\author{
Marwa Ben Slimene \\ SIME Laboratory, \\ Ecole Nationale Supérieure \\ d' Ingénieurs (ENSIT), \\ University of Tunis, Tunisia
}

\author{
Mohamed Arbi Khlifi \\ Hail University, Community College, \\ Hail, Saudi Arabia \\ and SIME Laboratory, \\ Ecole Nationale Supérieure \\ d' Ingénieurs (ENSIT), \\ University of Tunis, Tunisia
}

\begin{abstract}
This paper presents the transient stability analysis of a photovoltaic (PV) system with account shading effects. Voltage and transient stability effect of PV system are assessed functions of an experimental study. The current advances in shading effect and temperature control of $\mathbf{P V}$ panels are studied. The study is performed on modeling and simulation of PV system with account shading effect. A shading effect system is introduced to reflect the transient response characteristics of $P V$ generation model. An experimental setup is designed, constructed and assembled. The setup is provided with the necessary measuring instruments to carry out the required tests. A perspective on the other shading techniques for PV panels will be discussed in this paper.
\end{abstract}

Keywords-stability analysis; static/transient voltage stability; grid connected photovoltaic systems; shading effect

\section{INTRODUCTION}

Due to the growing demand on electricity, the limited stock and the rising prices of conventional sources (such as coal and petroleum), PV energy becomes a promising alternative as it is universal, freely available, environment friendly and has less operational and maintenance cost. Power generation using solar power increased dramatically because it is considered pollution free when compared to fossil fuel power generation. It has low maintenance cost, it is noise free and has no moving parts. Solar power uses solar panels to convert sun irradiation into electric energy using the PV effect. The output voltage of a solar panel is varying depending on sun irradiation and temperature [1]. Large scale solar power generation presents technical challenges on power system dynamics and operation due to its behavior: low inertia, power output variability. In response to an increase of PV capacity, the capacity of conventional synchronous generator needs to be reduced relatively. This leads to lower system inertia and higher generator reactance, and hence the power system transient stability may be negatively affected. Such concerns are more and more apparent for planning, security assessment, operation and protection setting of a power system.

Authors in [2] presented the impact of grid-connected PV generator on dynamic voltage stability of the IEEE-13 bus power system by considering solar intermittency, PV penetration level, and contingencies such as line outage and load increase. Author in [3] analyzed the effect of large scale PV on the IEEE-14 bus system on two criteria: constant load and maximum load, investigating the optimal location of solar PV generator and the maximum safe instantaneous penetration with considering some system stability and security constraints. As for transient stability, it occurs in response to large disturbance, such as three-phase fault. The occurrence of such a fault results in either sudden disconnection of the PV system or shut down of the PV inverters. Disconnecting a large number of PV causes a negative effect on power system transient stability. Authors in [4] studied the transient response characteristics of PV model connected to IEEE 9 bus system. Authors in [5] analyzed the effect of diversity in power sources, fault location, load characteristics, and low-voltage ride-through on transient stability of IEEE 9 bus system with connected high penetration PV system. Authors in [6] investigated the transient response of solar PV generation of the MV Tunisian power system. The response of the solar farms to short-circuits shows the capacity of the PV farms in withstanding voltage dips and their participation in voltage support. Therefore, these simulations demonstrate that these types of solar photovoltaic generation are recommended to better meet the requirements of some network operators.

It has been shown that overall efficiency of PV cells drops steeply with temperature increase, with a rate of decrease ranging from $0.25 \%$ to $0.5 \%$ per Celsius degree, depending on the cell material used, it has been observed that high temperatures decrease greatly the working life of the whole PV system. Cooling techniques produce more power, and reduce the cost of generally expensive PV equipment. It has been shown that a sizable portion of power can be gained, up to a total of 5\% [7]. Authors in [8] investigated the improvement of voltage stability in IEEE 9 bus system as an impact of connecting a PV system to the system including the impact of temperature variation based on the location which was modeled in MATLAB. In this work, we focus on PV systems operating under high temperature environment such as hot desert conditions. The purpose is twofold: At first, study and 
modeling of the PV system is detailed. Then, voltage stability, transient stability and general performance are assessed of an experimental study. The study is performed on the IEEE 9-bus system model. The simulation platform is established in DIgSILENT/PowerFactory consisting of PV arrays, power inverters, transformers, transmission lines and grid as shown in Figure 1 [9].

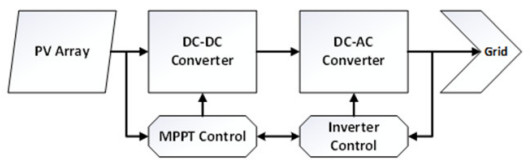

Fig. 1. Block diagram of a PV System

\section{MODELLING OF A SOLAR PV SYSTEM OPERATION}

\section{A. DC/DC Boost Converter and Circuit of Solar Cell}

Figure 2 shows the DC chopper type boost converter consisting of diode $\mathrm{D}$, inductor $\mathrm{L}$, capacitor C, IGBT switch S, input voltage source and load resistance $R . V_{\text {in }}$ is the input voltage and the $\mathrm{V}_{\mathrm{o}}$ is the output voltage. The circuit used in this paper is presented in Figure 3. The PV module used in this system is a 24 multi-crystalline solar cell in series able to provide $32.2 \mathrm{~W}$ of maximum power. The circuit is completed by a parallel resistor $R_{s h}$ and a series resistor $R_{s}$. Figure 4 illustrates the instantaneous evolution of voltage and current. Simulations were performed in the same conditions of irradiation and time.

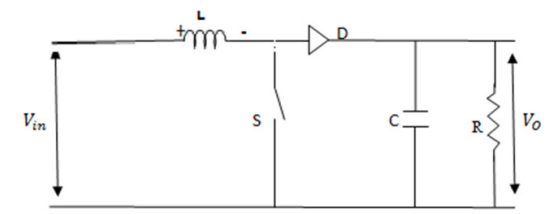

Fig. 2. Configuration of DC/DC boost converter

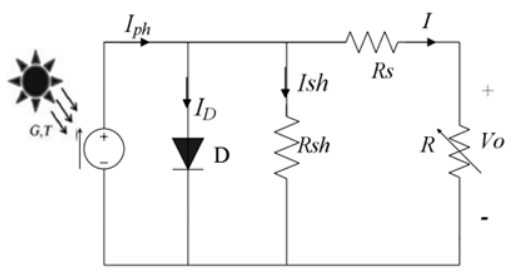

Fig. 3. Circuit of PV Cell

The PV model is based on an equivalent circuit with a single diode shown in Figure 3. The diode based model with a controlled current source can be used to predict the behavior of the PV system under various levels of irradiation, temperature and load conditions. The parallel resistance $R_{\text {sh }}$ represents the leakage currents at the cell edges. The series resistance $R_{s}$ represents the voltage drop during the transfer of charge carriers from the semiconductor junction to the external contacts. With the variation of cell temperature and irradiation, there will be considerable change in voltage and current which result in the increase or decrease of PV cell power output [10$11]$.
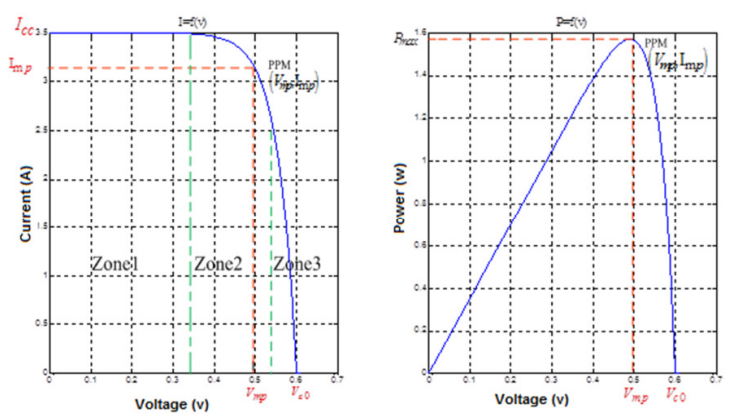

Fig. 4. V-I characteristics

\section{B. Stability Models}

Load flow model: The load flow analyzes the controlled variables as a result of load flow calculation. In DIgSILENT/PowerFactory there are preferred control conditions supported by the built in PWM converter. The chosen control mode for this study is the $\mathrm{V}_{\mathrm{DC}}-\mathrm{Q}$. Typical control modes are:

- $\mathrm{V}_{\mathrm{ac}}$-phi: Specifies magnitude and phase of the AC-terminal. Typical control modes for motor-side converters in variable speed drive applications.

- PWM-phi: Load-flow setup without control. The pulsewidth modulation factor is directly set in magnitude and phase.

- $\mathrm{V}_{\mathrm{dc}}-\mathrm{Q}$ : Specifies DC-voltage and reactive power output/flow. Typical applications: STATCOM, shunt converter of UPFC, grid-side converter of doubly-fed induction machines, VSC-HVDC applications.

- $\quad \mathrm{V}_{\mathrm{ac}}-\mathrm{P}$ : Specifies AC-voltage magnitude and active power. This is equivalent to a "PV" characteristic of conventional synchronous machines. Typical applications: Grid-Side converter of converter driven synchronous machines, VSCHVDC.

- P-Q: Specifies P and Q at the AC-side. This control mode is equivalent to a "PQ"- characteristic of synchronous machines. Typical applications: Same as " $\mathrm{V}_{\mathrm{ac}}-\mathrm{P}$ ".

- $\mathrm{V}_{\mathrm{dc}}-\mathrm{V}_{\mathrm{ac}}$ : Specifies DC- and AC-voltage. Typical applications similar ' $\mathrm{V}_{\mathrm{dc}}-\mathrm{Q}$ ' to the control mode: STATCOM, grid-side converter of doubly-fed induction machines, VSC-HVDC applications.

The Western Electricity Coordinating Council (WECC) Renewable Energy Modeling Task Force recommends the use of the single-machine equivalent representation shown in Figure 5 to model central-station PV plants in WECC based cases [11]. This representation is also considered adequate for positive-sequence transient stability simulations at the bulk system level. If present, the interconnection transmission line, station transformer and plant-level reactive compensation should be represented explicitly, according to established industry practice. In this model, the equivalent generator 
represents the total generating capacity of all the inverters, the equivalent pad-mounted transformer represents the aggregate effect of all step-up transformers, and the equivalent collector system branch represents the aggregate effect of the PV plant collector system. With the proper model parameters, this model should approximate PV plant load flow characteristics at the interconnection point, collector system real and reactive losses and voltage profile at the terminals of the "average" inverter in the PV plant. The recommended load flow representation for high penetration PV scenarios is shown in Figure 6 [12].

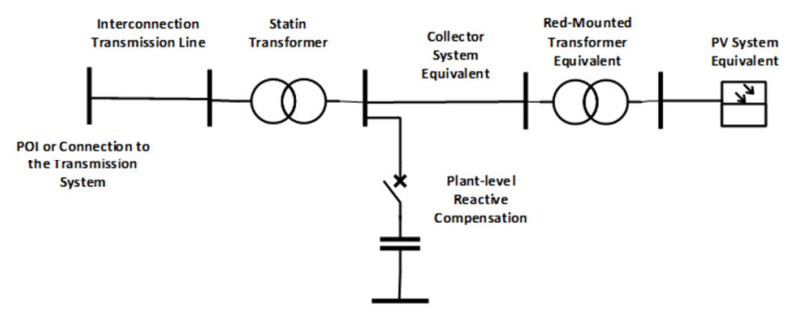

Fig. 5. Single-machine equivalent load flow representation

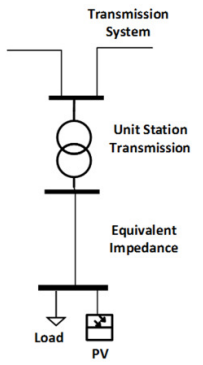

Fig. 6. Recommended load flow model for high PV penetration

\section{RESULTS AND DISCUSSION}

\section{A. Experimental Study of Shading Effects on PV System}

Shade covered one complete cell area of the panel. In order to show the effect of the partial shadow many scenarios have been studied using the PV panel. A photograph of the PV with a water cooling system is shown in Figure 7.

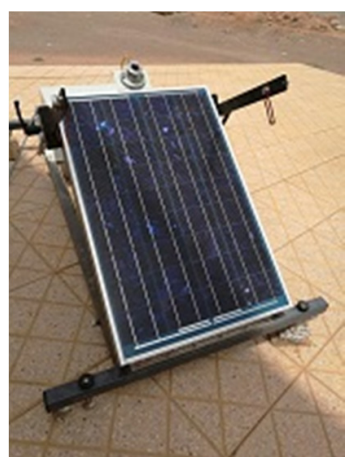

Fig. 7. Photograph of the PV panel

In a closed-loop water system, the incoming potable water is routed to water storage through valve, the cold water in the tank is pumped to the PV with water cooling system and the hot water produced in it flows to the water storage. The setup is provided with the necessary measuring instruments to carry out the required tests. A solar power meter of type AMPROBE (model SOLAR-100) was used to measure the instantaneous value of the total incident solar radiation intensity $\left(\mathrm{S}, \mathrm{W} / \mathrm{m}^{2}\right)$. Voltage, current and resistance were measured with a digital multimeter and rheostat connected with a data logger.

The experimental investigation took place during the clear days of June. Figure 8 shows the variation of array voltage with incident solar intensity (S). Figure 9 presents the variation of array current with time. Figure 10 shows the experimental results of both characteristics voltage and current. From this curve, this situation may also result in the development of hotspots in the panel. Such situations must be avoided as they may not only cause drop in power output and efficiency but also damage the cells permanently. The experimental and the computational study are in good agreement. The computational study will be more close to the experimental value if the setup is modeled inside an enclosure with actual PV.

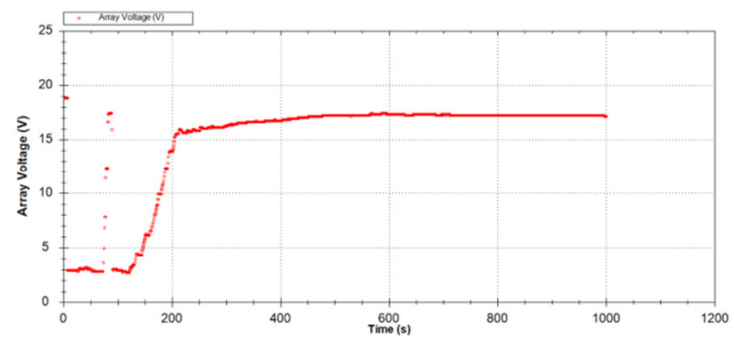

Fig. 8. Array voltage curve

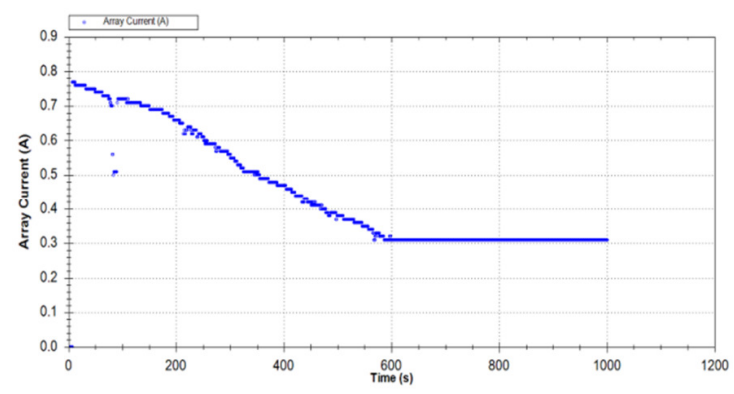

Fig. 9. Array current curve

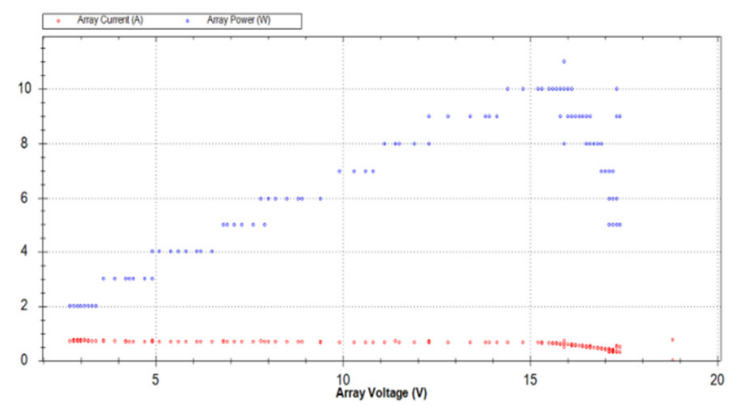

Fig. 10. Array current and voltage (I-V) characteristic

\section{B. Transient Stability Analysis of the PV System}

We used the IEEE 9-bus standard system model which has 3 synchronous generators, 3 large equivalent loads with a total 
of $315 \mathrm{MW}$ and 115MVAR connected in a meshed transmission network through 6 transmissions lines, and 3 two-winding power transformers (Figure 11). The base MVA is 100 and system frequency is $\mathrm{f}_{\mathrm{s}}=60 \mathrm{~Hz}$. The base $\mathrm{KV}$ levels are $13.8 \mathrm{kV}$, $16.5 \mathrm{kV}, 18 \mathrm{kV}$, and $230 \mathrm{kV}$. The line complex powers are around hundreds of MVA each. For system data see [13]. The model was chosen mainly to investigate the voltage stability. The modified IEEE 9-bus test system schematic is shown in Figure 11. The synchronous generator in bus 3 is replaced by an aggregated model of PV generator. The reactive power of the PV generators is not plotted for all simulations because the $\mathrm{PV}$ generator is operating at unity power factor and therefore the reactive power consumed or produced by the PV generator is equal to zero. The characteristic parameters of PV array are listed in Table I.

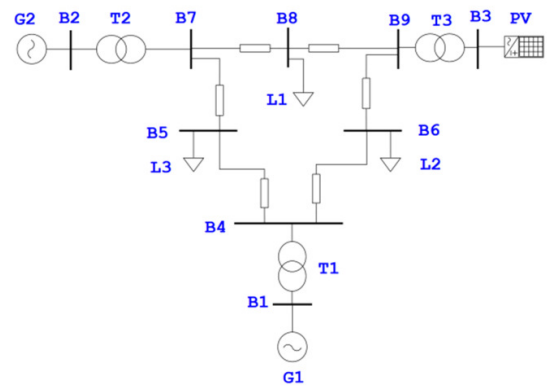

Fig. 11. Modified IEEE 9-bus system with PV system connected at bus 3

TABLE I. PV ARRAY PARAMETERS [9]

\begin{tabular}{|c|c|c|}
\hline Parameter & Symbol & Value \\
\hline Rated apparent power & $\mathrm{S}_{\mathrm{n}}$ & $0.5 \mathrm{MVA}$ \\
\hline Rated Power of the panel & $\mathrm{P}_{\mathrm{pk}}$ & $500 \mathrm{~kW}$ \\
\hline Rated Voltage at MPP & $\mathrm{U}_{\mathrm{mpp}}$ & $80 \mathrm{~V}$ \\
\hline Rated Current at MPP & $\mathrm{I}_{\mathrm{mpp}}$ & $6 \mathrm{~A}$ \\
\hline Open Circuit Voltage & $\mathrm{U}_{\mathrm{oc}}$ & $90 \mathrm{~V}$ \\
\hline Short-Circuit Current & $\mathrm{I}_{\mathrm{sc}}$ & $\mathrm{A}$ \\
\hline
\end{tabular}

For dynamic simulations, a dynamic model of the power system is necessary and load flow data are not sufficient. In order to obtain a dynamic model of the test system from Figure 1 , the dynamic models of generators, governors and automatic voltage regulators are included in the overall system model. The system is modeled in DIgSILENT/PowerFactory. Block diagrams of these models including parameter values for the IEEE 9 bus test system are shown in [13]. The system is simulated with varying temperature inputs and disturbances and analyzed under various operating conditions. The focus is to investigate the impact of various variables on the fault response. During simulation, it is studied how different controllers perform under various circumstances and how far they contribute in the minimization of voltage deviation in the system.

\section{1) Load Flow Results}

In load flow studies, PV generators are commonly assimilated to solar PV integrated PV type generator bus due to their active power generation and voltage control capability. When their reactive generation limits are reached, they are considered load buses. We have represented the PV according to this hypothesis. To create a realistic steady state operating point, this system was modeled in steady state and the load flow results are given in Figure 12.

(a)

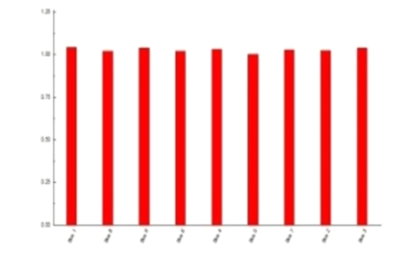

(b)

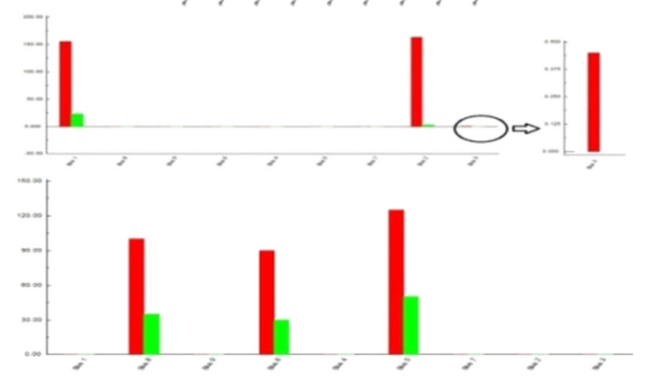

Fig. 12. Load-flow results: (a) Voltage magnitude, (b) generation (red: active power in MW, green: reactive power in MW), (c) general load (red: active power in MW, green: reactive power in MW)

The results show that the bus voltages for every node are within the acceptable range, i.e. between 0.93p.u. and 1.07p.u. and no overvoltage is detected as illustrated in Figure 12(a). The active and reactive powers injected to the different nodes are shown in Figure 12(b). The active and reactive powers injected to the loads are represented by the histogram in Figure 12(c). Note that all the reactive power consumption is supplied by the source 1 'Swing bus'.

\section{2) Dynamic Simulation}

Figures 13(b) and 13(c) show the power output of the PV generator under specific environmental conditions and time (during 10:00-16:00). In addition, these figures indicate that for peak temperature $\left(58^{\circ} \mathrm{C}\right)$ at $13: 45$, the power is $0.375 \mathrm{p}$.u. The current values change following the power changing values while the voltage values decrease gradually as shown in Figures 13(d) and 13(e). The default operating mode of the inverter is with fixed unity power factor. However, the generator reactive power will be $\mathrm{Q}_{\max }=\mathrm{Q}_{\min }=0$ as shown in Figure 13(c).

\section{3) Fault Analysis}

Fault occurs when temperature drops to zero in conditions such as extreme and sudden changes in whether as shown in Figure 14. In time between 13:00 and 14:00, and in case of using cooling system on PV system, the active power raises to the peak value of 0.47 p.u. (Figure $14(\mathrm{~b})$ ) and drops to the minimum value of 0.385 p.u. The voltage across the PV array drops to a minimum value of $620 \mathrm{~V}$ at the time of zero temperature (Figure 14(c)), while the current supplied by it rises to the maximum value of $680 \mathrm{~A}$ following the change of the active power delivers by PV array as shown in Figures 14(d) and 14(b). Thus, more active power is delivered by the PV system when the temperature is decreased by using a cooling system or as impact of specific weather conditions. 


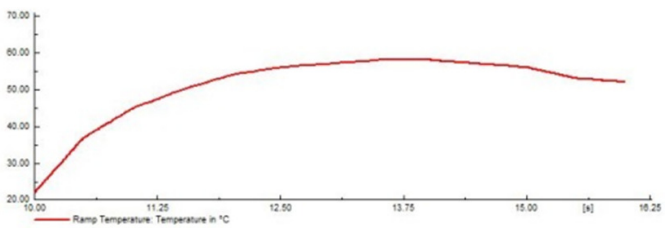

(a)

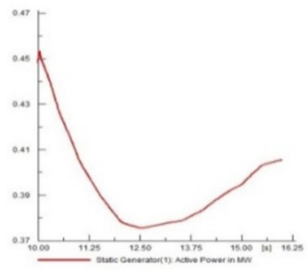

(b)

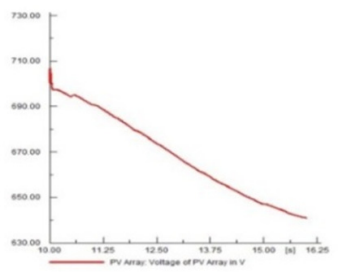

(d)

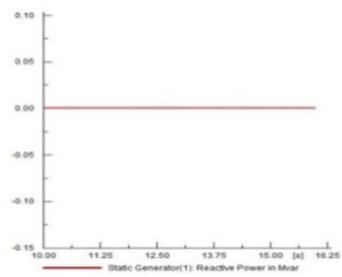

(c)

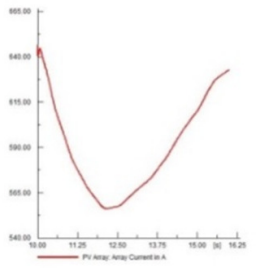

(e)
Fig. 13. System response in base case: (a) Ramp temperature, (b) and (c) power output of the PV generator, (d) PV voltage and (e) PV current

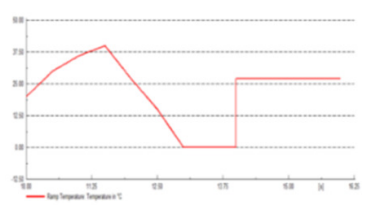

(a)

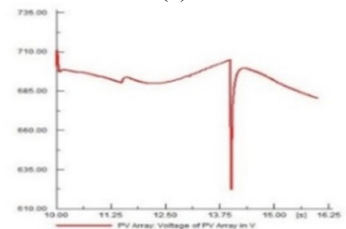

(c)

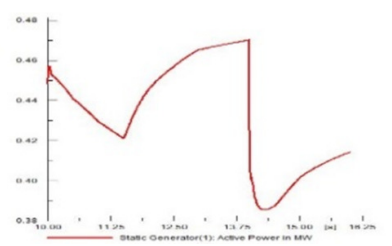

(b)

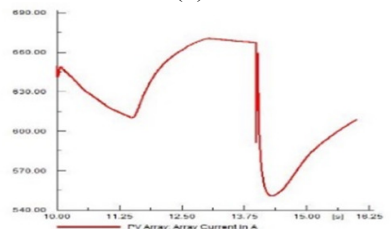

(d)
Fig. 14. PV generator response to fault: (a) Ramp temperature, (b) power output of the PV generator, (c) PV voltage and (d) PV current

\section{4) Transient Stability Simulation}

In this section, the dynamic interaction between the PV generator with power transmission system during and immediately after grid faults is illustrated and explained. The transient stability studies are conducted by applying a sudden three-phase short-circuit near the PV generator at the highvoltage terminals of the generator transformer at $\mathrm{t}=13.30$ with a fault clearance time of $150 \mathrm{~ms}$ by permanent isolation (tripping the relays). During the fault, it is assumed that the PV operates at its rated capacity with unity power factor. The short circuit path has an impedance $Z_{\text {fault }}=0$ p.u. Figures $15(a)$ and $15(\mathrm{~b})$ present the PV active and reactive power during the pre-fault, fault and post fault phases which improve the voltage profile as shown in Figure 15(c). Before the fault is applied, the active power output of the PV is $0.45 \mathrm{MW}$ while the reactive power output is kept constant at 0.0MVar, while the initial terminal voltage of the PV is 1.03 p.u. It is observed that when the short circuit occurs in the middle of line 5 (between Bus 8 and Bus 9), voltage responses indicate significant transient voltage drop profile in PV bus. The voltage in PV bus suddenly drops to a value of 0.08 p.u. and recovers once the short circuit is cleared. In the period of the utility voltage recovery, reactive power injected from the PV generation fluctuates and reaches the setting value of the protection. Thus, the reactive power injection curve improves voltage profile and the ride-through capability as shown in Figure 15(c). As the active power is reduced, the power control can be implemented to fulfill grid code requirements when the transients have decayed. After fault clearance, the PV system can continue with nominal operation. Thus, the PV panel connected to the grid increasing the ride-through capacity. This result is important because it indicates that the PV generator has a significant impact on the LVRT and the stability of the associated power system.

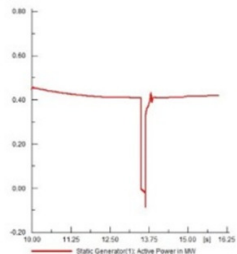

(a)

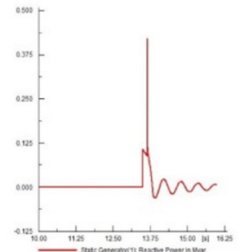

(b)

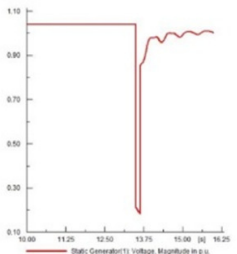

(c)
Fig. 15. System response of the to fault event: (a) PV active power, (b) PV reactive power, (c) Voltage

\section{CONCLUSION}

In this paper, the DC/DC converter, the circuit of solar cell of the PV module and their I-V characteristic are presented at various temperatures and irradiances. Further, some aspects of stability issues of PV systems operating under high temperature environment were investigated. An experimental study of shading effects on the PV system has been presented. Voltage stability, transient stability and general performance were assessed as functions of an experimental temperature profile. The study on the effects of temperature variation on the transient stability of the system was performed on the IEEE 9bus system model. The simulation platform was established in DIgSILENT/ Power Factory consisting of PV arrays, power inverters, transformers, transmission line and grid. The experimental results are in good agreement with the computational results.

\section{REFERENCES}

[1] M. A. Khlifi, "Study and Control of Photovoltaic Water Pumping System", Journal of Electrical Engineering and Technology, Vol. 11, No. 1, pp. 117-1240, 2016

[2] Z. A. Kamaruzzaman, A. Mohamed, "Dynamic voltage stability of a distribution system with high penetration of grid-connected photovoltaic type solar generators", Journal of Electrical Systems, Vol. 12, No. 2, pp. 239-248, 2016

[3] C. V. Chandran, "GA Based Optimal Control for Maximizing PV Penetration at Transmission”, Student Journal of Energy Research, Vol. 1, No. 1, ArticleNo 3, 2016 
[4] L. Qu, D. Zhao, T. Shi, N. Chen, J. Ding, "Photovoltaic Generation Model for Power System Transient Stability Analysis", International Journal of Computer and Electrical Engineering, Vol. 5, No. 3, pp. $297-$ 300, 2013

[5] M. Yagami, S. Ishikawa, Y. Ichinohe, K. Misawa, J. Tamura, "Transient Stability Assessment of Synchronous Generator in Power System with High Penetration Photovoltaics (Part 2)”, IEEE 2013 International Conference on Electrical Machines and Systems, Busan, South Korea, October 26-29, 2015

[6] S. Abdelaziz, B. K. Khadija, E. Mohamed, "Impact of Large Scale Photovoltaic Generation on Voltage Stability in Distribution Networks", European Journal of Electrical Engineering, Vol. 18, No. 1-2, pp. 117 138, 2016

[7] H. Hussein, A. Aloui, B. AlShammari, "ANFIS-based PI controller for maximum power point tracking in PV systems", International Journal of Advanced and Applied Sciences, Vol. 5, No. 2, pp. 90-96, 2018

[8] S. A. G. Stella, T. K. M. Babu, K. Gnanambal,“Capacity and Location Effects of Photo Voltaic Power Generators on Power Systems Stability", Advances in Natural and Applied Sciences, Vol. 9, No. 17, pp. 336-342, 2016

[9] H. Jerbi, "Design and performance analysis of a PV solar powered water pumping system", International Journal of Advanced and Applied Sciences, Vol. 4, No. 5, pp. 127-132, 2017

[10] B. M. Al Shammari, M. A. Khlifi, "Analysis of DC $\backslash D C$ Converter of Photovoltaic System with MPPT Algorithms Comparison", 19th International Conference on Solar Energy and Energy Storage, Copenhagen, Denmark, October 2-3, 2017

[11] S. Soni, G. G. Karady, M. Morjari, V. Chadliev, "Comparison of Full and Reduced Scale Solar PV Plant Models in Multi-Machine Power Systems. Conference", 2014 IEEE PES T\&D Conference and Exposition, Chicago, IL, USA, July 24, 2014

[12] M. H. Selamat, A. H. Ahmad, "Application of dye sensitized solar cell (DSSC) from dammar carbon - Fe2O3 (Iron (III) Oxide) composite counter electrode", International Journal of Advanced and Applied Sciences, Vol. 3, No. 7, pp. 35-40, 2016

[13] A. Salah, A. K. Mohamed, D. Azzedine, "Voltage and Frequency Regulation for an autonomous Induction Generators in Small Wind Power Plant", International Journal of Advanced and Applied Sciences, Vol. 6, No. 1, pp. 1-7, 2019 